\title{
La distribución de competencias entre el Estado y las Comunidades Autónomas en relación con la declaración y gestión de los Es- pacios Naturales Protegidos. La STC 102/1995, de 26 de junio
}

\author{
Rosario Laza y Laza \\ Departamento de Derecho Administrativo. \\ Universidad de Sevilla
}

Sumario: I. INTRODUCCIÓN. II. LA PROTECCIÓN DEL MEDIO AMBIENTE Y EL MARCO CONSTITUCIONAL DE DISTRIBUCIÓN DE COMPETENCIAS EN LA MATERIA. III. COMPETENCIA PARA DECLARAR Y GESTIONAR LOS ESPACIOS NATURALES PROTEGIDOS: a) Espacios Naturales Protegidos en terrenos contemplados en el art. 3 de la Ley de Costas; b) Espacios Naturales Protegidos supracomunitarios; c) Parques Nacionales.

\section{INTRODUCCIÓN}

La STC 102/1995, de 26 de junio ${ }^{1}$, resuelve seis recursos de inconstitucionalidad y ocho conflictos de competencia interpuestos contra la Ley 4/1989, de 27 de marzo ${ }^{2}$, de conservación de los espacios naturales y de la flora y fauna silvestres, caza y pesca, y contra tres reglamentos que la desarrollan. Solamente la acumulación de ese extenso número de recursos y conflictos nos da una idea de la complejidad y amplitud de la Sentencia que comentamos. Nuestra pretensión no es ofrecer un análisis exhaustivo y completo de la misma, sino centrarnos sólo en lo referente a la impugnación de la Disposición Adicional Quinta de la Ley 4/1989 en cuanto que considera básicos los arts. 21.3 y 4 y 22.1 de la misma; el TC, en su fallo, declara nula dicha Disposición ${ }^{3}$.

Por lo último dicho, ha de quedar claro que nos interesa especialmente estudiar la respuesta que el Tribunal da a los seis recursos de inconstitucionalidad ${ }^{4}$

\footnotetext{
Vid. BJC n. 171 (1995), págs. 5 y ss.

2 BOE n. ${ }^{\circ}$ 74, de 28 de marzo de 1989.

3 Vid. sobre el contenido y alcance de la Ley 4/1989 a A. PÉrez Moreno, «Los Espacios Naturales Protegidos» en $R A A P$, n. $^{\circ} 10,1992$, pág. 16 y ss.

4 Recursos n. ${ }^{\text {os }} 1220,1232,1238,1239,1260$ y $1268 / 1989$.
} 
interpuestos por el Gobierno Vasco, la Junta de Andalucía, el Gobierno de Canarias, la Generalidad de Cataluña, la Junta de Galicia y el Parlamento de Catalufia, respectivamente. El objeto de dichos recursos, en lo que a nosotros nos atañe, es solicitar la declaración de nulidad de la Disposición Adicional Quinta de la Ley 4/1989 en cuanto que considera «normas básicas, a los efectos de lo previsto en el art. 149.1.23. ${ }^{\circ}$ CE», entre otros, los arts. 21.3 y 4 y 22 del mismo texto legal ${ }^{5}$. Esto nos lleva a situar la cuestión de fondo que debemos dilucidar en un problema de distribución de competencias entre la Administración del Estado y las Comunidades Autónomas.

\section{LA PROTECCIÓN DEL MEDIO AMBIENTE Y EL MARCO CONSTITUCIONAL DE DISTRIBUCIÓN DE COMPETENCIAS EN LA MATERIA}

El título competencial general que afecta a la distribución de materias entre ambas instancias administrativas es la atribución al Estado de competencia exclusiva para el establecimiento de ula legislación básica sobre protección del medio ambiente, sin perjuicio de las facultades de las Comunidades Autónomas de establecer normas adicionales de protección’ (art. 149.1.23. ${ }^{\circ} \mathrm{CE}$ ). En este marco constitucional las Comunidades Autónomas de primer grado han asumido competencia para el desarrollo legislativo y la ejecución en relación con la protección del medio ambiente - el art. 15 del Estatuto de Autonomía de Andalucía así lo establece-; mientras que las de $2 .^{\circ}$ grado han utilizado en sus Estatutos diversas fórmulas teniendo presente que su marco constitucional es el art. 148.1.9. ${ }^{\circ} \mathrm{CE}$, según el cual atribuirse «la gestión del medio ambiente» ${ }^{6}$. Este esquema, sin embargo, se hace más complejo al tener que tener en cuenta otros títulos competenciales "afines» como es la protección de los espacios naturales, materia asumida como competencia exclusiva por las Comunidades de Andalucía, Aragón, Canarias, Cataluña, Navarra y Valencia ?

\footnotetext{
5 En concreto, la impugnación de los dos preceptos sólo se lleva a cabo por el Gobierno Vasco, la Junta de Andalucia y la Generalidad y el Parlamento catalán, siendo las instituciones catalanas las más radicales en la exposición de su demanda.

6 Al aprobarse la Ley Orgánica 9/1992, por la que se transfirieron competencias a las Comunidades de Aragón, Baleares, Cantabria y Castilla y León, se pretendió nivelar en este aspecto las Comunidades a quienes se transfieren competencias con aquellas otras que ya las disfrutaban, por lo que el esquema general de reparto de competencias en la materia queda dibujado en función de lo "básico» y su udesarrollo legislativo y ejecucións. Las Leyes Orgánicas 1 a 4 y 6 a 11/1994, de 24 de marzo, incorporan el contenido de la Ley Orgánica 9/1992 a los Estatutos de Autonomía de Asturias, Cantabria, La Rioja, Murcia, Aragón, Castilla-La Mancha, Extremadura, Islas Baleares, Madrid y Castilla y León.
}

7 Vid., al respecto, el art. 13 Estatuto de Autonomia de Andalucia, según el cual nuestra CA ostenta «competencia exclusiva sobre espacios naturales protegidos... sin perjuicio de lo dispuesto en el número 23, apartado 1, del art. $149 \mathrm{CE}$. 
LA DISTRIBUCIÓN DE COMPETENCIAS ENTRE EL ESTADO Y ...

En este punto es importante descubrir el grado de incidencia que la competencia exclusiva del Estado recogida en el art. 149.1.23. ${ }^{\circ} \mathrm{CE}$ tiene sobre la competencia autonómica:

«...En virtud de la competencia sobre espacios naturales protegidos, las $\mathrm{Co}$ munidades Autónomas que la tengan atribuida podrán dictar normas de protección y conservación de estos espacios y realizar la actividad de ejecución que estimen pertinente, siempre que respeten la legislación básica del Estado sobre protección del medio ambiente.» ${ }^{8}$.

Muy ilustrativa resulta la caracterización que de la materia a la que se refiere el art. 149.1.23. ${ }^{\circ} \mathrm{CE}$ hace el Abogado del Estado en sus Alegaciones a los recursos de inconstitucionalidad contra la Ley 4/1989:

«...el centro de gravedad de la norma competencial no es tanto el término medio ambiente como el de protección; se trata de un título finalista o teñido teleológicamente. De ahí que exista conexión entre el art. 149.1.23. ${ }^{\circ} \mathrm{CE}$ y el art. 45 de la misma norma. Existe, pues, un concepto constitucional unitario de medio ambiente, que habrá de determinarse conforme a los tratados y acuerdos internacionales, pues es aquí aplicable la regla del art. 10.2 CE. El régimen protector de los espacios naturales, así como el de la fauna y flora silvestres, forma parte de la protección del medio ambiente..) 9

Ésta y no otra es la razón por la que la competencia autonómica sobre espacios naturales protegidos ha de verse limitada o enmarcada en el art. 149.1.23. $\mathrm{CE}$. Una idea muy parecida, aunque más desarrollada, es recogida en el FJ 7 STC 102/1995, que lleva por título «La protección del medio ambiente: Dimensión funcional. Protección, conservación y mejoramiento.» ${ }^{10}$.

\section{COMPETENCIA PARA DECLARAR Y GESTIONAR LOS ESPACIOS NATURALES PROTEGIDOS}

Antes de entrar a conocer el tratamiento jurisprudencial del contenido de los arts. 21 y 22 Ley $4 / 1989$ es oportuno dejar constancia del concepto legal de

8 Vid. FJ 3 STC 102/1995 en BJC 171 (1995), pág. 31; citándose también SSTC 64/1982, 69/1982, $82 / 1982$ y $170 / 1989$.

9 Vid. Antecedentes n. 99 STC 102/1995, de 26 de junio, en BJC 171 (1995), pág. 24.

10 Una información exhaustiva y detallada sobre el marco constitucional de distribución de competencias en protección del medio ambiente puede encontrarse en A. A. PÉrEZ ANDRÉs, «Las tensiones originadas por la nueva ordenación de los Espacios Naturales Protegidos», RAAP, n. ${ }^{\circ} 16$, págs. 81-83; en especial, vid. nota (6) por la información bibliográfica que aporta. 
Espacio Natural Protegido, así como de su clasificación: para el art. 10 Ley 4/1989, los Espacios Naturales Protegidos son «aquellas zonas del territorio nacional, incluidas las aguas continentales, y los espacios marítimos sujetos a la jurisdicción nacional, incluidas la zona económica exclusiva y la plataforma continental, que contengan elementos y sistemas naturales de especial interés o valores naturales sobresalientes»; y el art. 12 los clasifica en Parques, Reservas Naturales, Monumentos Naturales y Paisajes Protegidos.

Pues bien, según el art. 21.1 de la Ley «la declaración y gestión de los Parques, Reservas Naturales, Monumentos Naturales y Paisajes Protegidos corresponderá a las Comunidades Autónomas en cuyo ámbito territorial se encuentren ubicados»». Y según el apartado $2 .^{\circ}$, las Comunidades Autónomas con competencia exclusiva sobre Espacios Naturales y con competencia para dictar normas adicionales de protección en materia de protección del medio ambiente, «podrán establecer, además de las figuras previstas en los arts. anteriores, otras diferentes regulando sus correspondientes medidas de protección».

El apartado primero establece una regla general en relación con las facultades gestoras sobre los Espacios Naturales Protegidos según la cual éstas se atribuyen a la Administración Autonómica. En primer lugar, no debe caber duda de que esta norma sólo se refiere a funciones puramente ejecutivas ( $y$ en ellas hemos de centrarnos en nuestro comentario), ya que:

«la declaración de que un espacio natural merece la protección prevista constitucionalmente, es un acto netamente ejecutivo que consiste en aplicar la legalidad, individualizándola, y, por tanto, es un acto materialmente administrativo.»"

Para el TC:

«el juego recíproco de las normas constitucionales y estatutarias pone de manifiesto que las facultades ejecutivas o de gestión en materia de me-

11 Vid. FJ 18 STC 102/1995, en BJC 171 (1995), pág. 42. Es importante aqui hacer un inciso para subrayar la naturaleza juridica que atribuye el TC a la declaración de un ENP. Nótese que dice «materialmente» administrativo con lo que subraya que en esencia forma parte de la gestión administrativa, aunque cabe la posibilidad de que formalmente se revista con apariencia de ley. Esto es precisamente lo que ocurre en el caso de la declaración de un Parque Nacional (vid. infra nota 25). Sobre el problema de la naturaleza jurídica de estas leyes singulares puede consultarse a Ignacio DE OTro, Derecho Constitucional. Sistema de fuentes (Ed. Ariel, Barcelona, 1987); en especial, el capitulo dedicado al concepto material de ley (págs. 162-181). Así, para este autor, «en la teoria juridica y en el lenguaje común suele darse el nombre de norma a la regulación abstracta, es decir, relativa a una pluralidad de acciones genéricamente determinadas, y se reserva la expresión orden para el mandato relativo a una conducta concreta... y no indica nada respecto a los destinatarios, pues tan orden es la que se dirige a un solo sujeto como la que impone el desalojo de un edificio para todos cuantos se encuentran en él en un determinado momenton (vid. pág. 180). 
dio ambiente, en general... corresponden a las Comunidades Autónomas y no al Estado..)

Esta función ejecutiva la encomiendan los Estatutos de Autonomía no sólo en el ámbito entero de la protección del medio ambiente, comprendidos los espacios naturales, trátese de las normas básicas como de las adicionales y de las que se dicten para su desarrollo, legislativas y reglamentarias, estatales o no, sino también en las diferentes facetas que conllevan la administración, la inspección y la potestad sancionadora.

Esta regla general de atribución de competencias a las Comunidades Autónomas, sin embargo, cuenta con tres excepciones:

\section{a) Espacios Naturales Protegidos en bienes contemplados en el art. 3 de la Ley de Costas}

Según el art. 21.3 Ley 4/1989, «la declaración y gestión de los Espacios Naturales Protegidos corresponderá al Estado cuando tengan por objeto la protección de bienes de los señalados en el art. 3 Ley 22/1988, de 28 de julio, de Costas». Para el TC, ni la titularidad del dominio público, ni la relevancia de estos bienes para el interés general confieren la competencia estatal ${ }^{13}$, ya que es la naturaleza jurídica de la actividad el único criterio válido para juzgar de su idoneidad constitucional, por lo que:

«la calificación de un segmento o trozo de la zona marítimo-terrestre como parte de un espacio natural protegible corresponde también a la Comunidad Autónoma en cuyo territorio se encuentre. Lo mismo cabe decir de la gestión, a los solos efectos de la protección del medio ambiente, sin que la posibilidad de interferencias recíprocas, fenómeno común en el ejercicio de competencias concurrentes sobre el mismo objeto para diferentes funciones, autorice a unificarlas mediante la absorción de una por la otra.) ${ }^{14}$.

12 Vid. FJ 18 STC 102/1995 (en BJC 171, pág. 41), que cita, a su vez, SSTC 149/1991 y 329/1993.

13 Cita el TC su S 149/1991, según la cual, «las facultades dominicales sólo pueden ser legítimamente utilizadas en atención a los fines públicos que justifican la existencia del dominio público, esto es, para asegurar la protección de la integridad del demanio, la preservación de sus características naturales y la libre utilización libre y gratuita, no para condicionar abusivamente la utilización de competencias ajenas y en lo que aquí más directamente nos ocupa, de la competencia autonómica para la ordenación territorial» (vid. FJ 20 STC 102/1995).

14 En este punto concreto el magistrado del TC D. Rafael de Mendizábal Allende, que formula voto particular a la Sentencia que comentamos, se muestra por completo de acuerdo con el parecer del Tribunal (vid. punto 4 Voto particular a STC 102/1995; BJC 171 (1995), pág. 53. 


\section{b) Espacios Naturales Protegidos supracomunitarios}

En cuanto al art. 21.4 Ley $4 / 1989^{15}$, en el mismo se ha separado una de las potestades administrativas - la declaración de un Espacio Natural cuyo territorio afecta a más de una $\mathrm{CA}$ - de las demás facultades gestoras. Estas otras sí se mantienen en manos autonómicas aunque bajo la coordinación del Estado, lo que implica que ante posibles discrepancias en cuanto a las decisiones administrativas que hayan de adoptarse, éste impondrá su criterio ${ }^{16}$.

\section{Quizás merezca cierto detenimiento la valoración del 2. ${ }^{\circ}$ párrafo:}

«...cae, a su vez, por conexión, aun cuando su contenido parezca razonable en principio como fórmula de colaboración, desde el momento en que desaparece la cabecera de la cual trae causa.» ${ }^{17}$.

Obsérvese que el Tribunal habla de fórmula de colaboración, no de coordinación, lo que se traduce en que las Administraciones autonómicas implicadas en la gestión de este tipo de Espacios Naturales Protegidos deberán desarrollar su actividad procurando encontrar fórmulas por las que, sin posibilidad de que ninguna instancia administrativa imponga su criterio a la otra u otras, la protección pública de los mismos sea eficaz y coherente. Es importante subrayar la coincidencia del parecer del Tribunal con el del Gobierno Vasco, para el que:

«el Estado podra dictar algunas normas básicas que articulen la participación de las Comunidades Autónomas en la declaración y establecimiento de las reglas de uso y gestión del Espacio Natural Protegido, pero no normas básicas sustantivas para esos espacios, pues el interés supracomunitario no es un título atributivo de competencia para el Estado, permitiendo sólo a éste encauzar el ejercicio de las competencias de las Comunida-

15 Que literalmente dispone: «Corresponderá al Estado la declaración de los Espacios Naturales Protegidos cuando éstos estén situados en el territorio de dos o más Comunidades Autónomas. En este supuesto se convendrá entre el Estado y las Comunidades Autónomas afectadas las modalidades de participación de cada Administración en la gestión del espacio natural de que se trate, correspondiendo al Estado la coordinación de dicha gestión y, en su caso, la presidencia de la Junta Rectoray.

16 Sobre el alcance de la potestad de coordinación interadministrativa puede consultarse a Pablo MENÉNDEZ, Las potestades administrativas de dirección y coordinación territorial. Ed. Civitas, Madrid, 1993, pág. 171. Según este autor, la coordinación lleva aparejada una imposición coactiva por parte del órgano o ente coordinante que se sitúa en posición de superioridad sobre el coordinado (vid. pág. 173). Por el contrario, la cooperación consiste en el ejercicio de las competencias propias de los Entes Territoriales, que necesariamente han de relacionarse para llevarlas a la práctica, de forma mancomunada, interviniendo ambas en un mismo proceso de decisión (vid. Eliseo AJA y otros, El sistema juridico de las Comunidades Autónomas. Ed. Tecnos, Madrid, 1985, pág. 410).

17 Vid. FJ 19 STC 102/1995 in fine. 
des Autónomas implicadas a través de las reglas de procedimiento indispensables para garantizar la participación equitativa de aquéllas en función de su interés respectivo y a fin de evitar el perjuicio que para el interés general podría derivarse de una falta de entendimiento entre las mismas (pero en ningún caso tal facultad de encauzamiento puede rebasar lo formal y adentrarse en aspectos sustantivos).. ${ }^{18}$.

La colaboración se institucionaliza, de acuerdo con el art. 20 Ley $4 / 1989$, mediante una Junta Rectora o Patronato; la participación del Estado como miembro en esa Junta es respetuosa con las competencias autonómicas en cuanto que forma parte de las facultades coordinadoras del mismo en el marco del art. 149.1.23. ${ }^{\circ} \mathrm{CE}$, pero no la extensión de dichas facultades a la gestión cotidiana del Espacio Natural desarrollada por dicha institución.

En resumidas cuentas, a mi modo de entender, el TC no admite que el Estado tenga potestad para declarar Espacio Natural Protegido una zona del territorio nacional por el mero hecho de que afecte a más de una $\mathrm{CA}$, pero sí posee facultades para diseñar (en el marco del establecimiento de la legislación básica sobre protección del medio ambiente) los procedimientos de colaboración y cooperación en la gestión del mismo que necesariamente han de utilizarse por las Comunidades Autónomas afectadas. Asimismo, puede participar como parte en la Junta Rectora o Patronato de dicho espacio natural supracomunitario.

\section{c) Parques Nacionales}

La tercera excepción al régimen general de distribución de competencias consiste en la existencia de un grupo de Espacios Naturales Protegidos que son declarados como Parques por una Ley de las Cortes Generales y cuya gestión se atribuye al Estado. Se trata de los Parques Nacionales ${ }^{19}$, regulados por los

\footnotetext{
18 Vid. Antecedentes punto 3, STC 102/1995; BJC 171 (1995), pág. 13.
}

19 El origen de la figura del Parque Nacional en el ordenamiento administrativo español se sitúa en la Ley Gasset de 1916, propuesta por el Marqués de Villaviciosa de Asturias y que estuvo en vigor hasta la Ley de Montes de 1957 (vid. al respecto F. LOPEZ RAMÓN, La conservación de la naturaleza: los espacios naturales protegidos, Bolonia, 1980). La STC 102/1995 realiza un sustancioso comentario sobre el contenido de esta norma al comienzo de su FJ 21 (vid. BJC 171 (1995), pág. 43). Con posterioridad se aprobó la Ley 15/1975 de 2 de mayo, de Espacios Naturales Protegidos (vid. un somero comentario al contenido de esta disposición legal en A. PÉrez Moreno, (Los Espacios Naturales Protegidos», op. cit., págs. 13 y 14) que ha estado vigente hasta la aprobación de la Ley 4/1989 que es objeto de impugnación ante el TC.

A la entrada en vigor de la Ley 4/1989 - 29 de marzo de 1989 - los Parques Nacionales ya declarados como tales eran ocho - Caldera de Taburiente, Doñana, Garajonay, Montaña de Covadonga, Ordesa y Monte Perdido, Tablas de Daimiel, Teide y Timanfaya - habiendo sido declarado con posterioridad el Parque Nacional Maritimo-terrestre del Archipiélago de Cabrera. 
arts. 22 y 23 de la Ley 4/1989; de dichos preceptos ha de subrayarse fundamentalmente el hecho de que la razón de ser de la declaración de estos Espacios por Ley ordinaria reside en que su conservación es de interés general de la Nación, de lo que se deriva también el que la gestión se atribuya a la Administración del Estado 20.

«No repugna, por tanto, al orden constitucional de competencias que puede corresponder al Estado, como titular de ese interés general de la Nación, la creación de tales Parques, para lo cual además se reconoce una facultad de propuesta a las Comunidades Autónomas, aunque no vinculante jurídicamente. ${ }^{21}$.

En cuanto a la gestión, el TC en el FJ 22, declara que ha de ser compartida por la Administración del Estado y las Administraciones de las Comunidades Autónomas afectadas, de lo que se deriva que el art. 22.1 de la Ley se considera inconstitucional parcialmente. La fórmula de colaboración que se propone para dichas Administraciones Territoriales es la diseñada en el art. 23: la creación de un $\mathrm{Pa}$ tronato en el que estén representadas todas las Administraciones Públicas implicadas en la gestión del Parque y con funciones de asesoramiento, promoción, seguimiento y control del mismo 22 .

Observamos, en cuanto a la capacidad expansiva del título competencial del Estado presente en este precepto y consistente en la declaración del Parque Nacional un paralelismo evidente con el mostrado en el art. 21.3 para los bienes de dominio público estatal del art. 3 de la Ley de Costas. Sabemos que en relación con el mismo el TC declaraba que:

«es opinión pacífica que la titularidad del dominio público no confiere, por sí misma, competencia alguna. Tampoco tiene tal virtud taumatúrgica la importancia de estos bienes para el interés general, valor colectivo donde estriba el fundamento de su calificación jurídica como públicos y de la adscripción de su dominio al Estado.» ${ }^{23}$.

\footnotetext{
20 Así lo señala el TC, para el que «la caracteristica que sirve para definirlos pone de manifiesto simultáneamente la concurrencia de un interés general para el conjunto de la Nación, cuya fuerza expansiva trasciende su importancia local hasta infiltrarse, diluirse y perderse en la trama y urdimbre de la estructura ecológica de la península o de sus archipiélagos» (vid. STC 102/1995, FJ 21, BJC 171 (1995), pág. 43).

21 Vid. FJ 21 in fine STC 102/1995, BJC 171 (1995), pág. 43.

22 Puede decirse que el papel de las Comunidades Autónomas en la gestión de los Parques Nacionales es muy parecido al del Estado en el de los Espacios supracomunitarios (vid. comentario sobre el art. 21.4 supra) con la salvedad de que a éstas no se les atribuye ninguna competencia para disponer procedimientos de colaboración o cooperación entre las Administraciones interesadas, como es natural en cuanto que dicha potestad del Estado se justifica en el art. 149.1.23. ${ }^{\circ} \mathrm{CE}$.
}

23

Vid. supra. 
Pues bien, el título competencial en manos del Estado en el supuesto presente se justifica también en el interés general de la Nación en la conservación de estos Espacios, y, sin embargo, en este caso el TC sí justifica y considera constitucional la quiebra de la regla general de distribución de competencias en la materia:

«La posibilidad, pues, de su mera existencia reúne todos los rasgos de lo básico por su carácter selectivo y primario en la materia como los reúne la configuración abstracta que actúa como presupuesto de hecho de la declaración.» ${ }^{24}$.

Sabemos que la vía por la cual el Estado condiciona la competencia exclusiva de algunas CC.AA. sobre los ENP y la competencia de desarrollo normativo y ejecución en materia de protección del medio ambiente que tienen atribuidas todas ellas, es la capacidad para establecer la «legislación básica» en esa misma materia (art. 149.1.23..$^{\circ}$ - esto es lo que da a entender el TC, en el FJ 21, cuando afirma que la existencia de los Parques Nacionales «reúne todos los rasgos de lo básico»-, por lo que es necesario que indaguemos hasta donde admite el mismo TC que actúe la "vis expansiva» de dicho título:

«La Constitución habla varias veces de bases, una de condiciones básicas, otra de normas básicas cuando enumera las distintas atribuciones que componen la competencia exclusiva del Estado, expresiones que tienen una referencia común, aun cuando con modulaciones diferentes. Para decirlo con pocas palabras, en las dos primeras predomina su dimensión material y en las últimas su aspecto formal que, además, se potencia cuando las Comunidades Autónomas tienen conferidos el desarrollo legislativo y la ejecución en la materia de que se trate, como es el caso de la protección del medio ambiente. Lo básico incorpora la acepción de fundamento o apoyo principal de algo, con vocación por la esencia, no de lo fenoménico o circunstancial, cuya finalidad consiste en "asegurar, en aras de intereses generales superiores a los de las Comunidades Autónomas, un común denominador normativo" (STC 48/1981) y, en la materia que nos ocupa, "el encuadramiento de una política global del medio ambiente" (STC 64/1982), haciendo viable la solidaridad colectiva y garantizando su disfrute por todos, asi como el correlativo deber de conservación en régimen de igualdad (art. $45 \mathrm{CE}$ ).

24 En un voto particular, Mendizábal Allende reconoce la «timidez» del TC al no restituir a «sus legitimos propietarios» la competencia de declarar y gestionar los ENP en el supuesto de los Parques $\mathrm{Na-}$ cionales (vid. pág. 4 Voto particular STC 102/1995, BJC 171 (1995), pág. 53). 
En consecuencia, la legislación básica ofrece un perímetro amplio por su formulación genérica con un contenido esencialmente normativo. Habrá de ser, en principio, un conjunto de normas legales, aun cuando también resulten admisibles - con carácter excepcional, sin embargo- las procedentes de la potestad reglamentaria que la Constitución encomienda al Gobierno de la Nación (art. $97 \mathrm{CE}$ ), siempre que resulten imprescindibles y se justifiquen por su contenido técnico o por su carácter coyuntural o estacional, circunstancial y, en suma, sometido a cambios o variaciones frecuentes e inesperadas. Ahora bien, el contenido normativo de lo básico en esta materia no significa la exclusión de otro tipo de actuaciones que exijan la intervención estatal, solución ciertamente excepcional a la cual sólo podrá llegarse cuando no quepa establecer ningún punto de conexión que permita el ejencicio de las competencias autonómicas o cuando además del carácter suprautonómico del fenómeno objeto de la competencia, no sea posible el fraccionamiento de la actividad pública ejercida sobre él y, aun en este caso, siempre que dicha actuación tampoco pueda ejercerse mediante mecanismos de cooperación y coordinación y, por ello requiera un grado de homogeneidad que sólo pueda garantizar su atribución a un único titular, forzosamente el Estado, y cuando sea necesario recurrir a un ente supraordenado con capacidad de intereses contrapuestos de sus componentes parciales, sin olvidar el peligro inminente de daños irreparables, que nos sitúa en el terreno del estado de necesidad. Se produce asi la metamorfosis del titulo habilitante de tales actuaciones, cuyo asiento se encontraria en la competencia residual del Estado (art. 149.3 CE), mientras que en situación de normalidad las facultades ejecutivas o de gestión en materia de medio ambiente corresponden a las Comunidades Autónomas dentro de su ámbito espacial y no al Estado (STC 392/1993)» ${ }^{25}$.

El TC da a entender que en los supuestos excepcionales en los que quiebra el carácter formal de la competencia estatal para establecer la legislación básica sobre protección del medio ambiente, extendiéndose las atribuciones del Estado hasta agotar la materia objeto de competencias admistrativas, el título habilitante se transforma, no pudiéndose hablar de «bases» o «legislación básical, sino de una competencia residual del Estado (art. 149.3 CE) que excluye toda participación de las Comunidades Autónomas. No puede decirse que éste sea el caso contemplado en el art. 22 de la ley pues el mismo TC admite que las Comunidades Autónomas tienen competencia para participar y colaborar en la gestión de dichos Parques; por todo ello, la autora de este comentario se une al parecer de Mendizábal Allende atreviéndome a desarrollarlo: De acuerdo con la natu- 
raleza y características del título competencial que al Estado reconoce el art. 149.1.23. ${ }^{\circ} \mathrm{CE}$, no me parece conforme con la Constitución que la declaración de un Parque Nacional como tal -acto meramente administrativo- pueda considerarse que ureúne todos los rasgos de lo básico». Sí es cierto que estos Espacios Naturales Protegidos, por la importancia que para la Nación representa su conservación, ostentan caracteres supracomunitarios que justificarian la asunción por el Estado de potestades de coordinación en la gestión de los mismos.

En cuanto a su declaración, la Ley 4/1989 sigue en este punto el sistema vigente ya con la Ley 15/1975, es decir, se sigue exigiendo que la misma se realice mediante una Ley de las Cortes Generales ${ }^{26}$. El uso de ese instrumento jurídico para declarar un Parque Nacional no garantiza un sistema de conservación coherente y uniforme, acorde con el interés general que lo justifica. Considero lesivo este sistema con el régimen de distribución de competencias en la materia, y ello, entre otras razones, porque no se arbitra un procedimiento administrativo en el que se garantice una verdadera participación de las Comunidades Autónomas con competencias sobre dichos Espacios. Es el Gobierno de la Nación quien presentará el proyecto de ley a Cortes, siendo en el seno del procedimiento de elaboración del mismo donde podría ubicarse la constancia del parecer de dichas Comunidades Autónomas, lo que, teniendo presente lo flexible y antiformalista de esta fase del procedimiento legislativo, no puede considerarse ni mucho menos suficiente garantía para el respeto de las competencias autonómicas. Por lo demás, el art. 22 prevé la posibilidad de que la apertura del procedimiento de aprobación de una de

\footnotetext{
26 Recientemente ha sido declarado Parque Nacional, por Ley 14/1991, de 29 de abril (BOE n. ${ }^{\circ} 103$, de 30 de abril), el Archipiélago de Cabrera. Es conveniente además advertir que la Ley 4/1989 deja abierta la posibilidad de que la declaración de los demás tipos de Espacios Naturales (enumerados en el art. 12 de la misma) se lleve a cabo por el mismo sistema -el art. 18.1 reconoce explicitamente el uso de esa técnica procedimental--; sin embargo, ha de tenerse presente que la Ley estatal dispone que previa a la declaración de un Parque o Reserva Natural por una CA debe aprobarse el Plan de Ordenación de los Recursos Naturales de la zona. Sobre este parámetro básico, la CA andaluza aprobó la Ley 2/1989, de 18 de julio (BOJA n. ${ }^{\circ}$ 60, de 27 de julio), según la cual es competencia del Consejo de Gobierno, a propuesta de la Agencia de Medio Ambiente, acordar la elaboración y aprobación de los Planes de Ordenación de Recursos Naturales - vid. art. 18.2- mientras que la declaración de los Parques y Reservas Naturales de Andalucia se lleva a cabo por los arts. 5 y 7 del mismo texto legal -complementado por el Inventario que figura en el Anexo al mismo-. Es indudable que la adopción de este sistema no respeta la regla general querida por la Ley estatal de Espacios Naturales Protegidos y además supone revestir con la forma de Ley un mero acto administrativo.

Una crítica al sistema expuesto puede encontrarse en F. GARRIDO FALLA, «Sobre posible inconstitucionalidad de la Ley 1/199l del Parlamento de las Islas Baleares (la Reserva del Ejecutivo)"), (RAP, n. ${ }^{\circ} 126$, 1991, págs. 513 y ss.), cuyas tesis recoge también A. A. Pérez ANDRÉs, "Las tensiones originadas...) (op. cit. supra), quien además analiza el problema desde el desarrollo que la CA de Andalucia ha llevado a cabo de la Ley 4/1989 (vid. sobre el particular págs. 110-112).
} 
REALA 271-272 (JULIO-DICIEMBRE, 1996)

estas Leyes-singulares se lleve a cabo mediante una propuesta no vinculante de las Comunidades Autónomas afectadas.

No cabe duda que de lo antedicho se deduce que la necesidad de respetar las competencias autonómicas para la gestión de los Parques Nacionales (dentro de la cual se encuentra también incluida la declaración) exige la regulación por la normativa básica del Estado en materia de protección del medio ambiente de un procedimiento de declaración de estos ENP en el que la decisión final quedase en manos del Gobierno, pero reconociendo en el seno del mismo a las CC.AA. afectadas una función consultiva —parcialmente vinculante— en su fase instructora. 